FORAMS 2006

\title{
Review of mangrove foraminifera from the Guaratiba tidal plain, Rio de Janeiro, SE Brazil, collected in the early 70's
}

\author{
Lázaro L. M. Laut ${ }^{1}$; Eduardo A. M. Koutsoukos² \& Maria Antonieta C. Rodrigues ${ }^{3}$ \\ ${ }^{1}$ Departamento de Geologia, LAGEMAR, UFF, Universidade Federal Fluminense, \\ Niterói, RJ,Brazil - laut@igeo.uff.br \\ ${ }^{2}$ PETROBRAS-CENPES, Cidade Universitária, Ilha do Fundão, 21941-598 \\ Rio de Janeiro, RJ, Brazil \\ ${ }^{3}$ Faculdade de Geologia, UERJ, Universidade do Estado do Rio de Janeiro, \\ Rio de Janeiro, RJ, Brazil
}

Guaratiba's mangrove is located in Sepetiba's Bay, south of Rio de Janeiro, Brazil. The Bay has great economical importance, not only for the location of one of the Brazilian major harbors, but also for its industrial and fishing activities. The ecosystem is ecologically important for its high productivity, retention of fine sediment, preventing channels silting and trapping of heavy metals. Therefore it's important to monitor the mangrove environment. The use of benthic foraminiferal assemblages has been enhanced lately as an important tool for these enviroments' characterization and monitoring, due to the sensitivity of these organisms to environmental alterations. The aim of this paper is a qualitative and quantitative analysis of benthic foraminiferal assemblages of Guaratiba's mangrove tidal channels sampled before the harbors construction, to obtain a background reference for future studies of environment monitoring.

Guaratiba's mangrove sediments were collected by PETROBRAS in 1977 and 1978. Seventeen sampling points distributed along the main tidal channels (Piracão River, Portinho River and Bacalhau Channel) were selected for foraminiferal analysis. The physical-chemical parameters salinity, $\mathrm{pH}$, temperature and suspending matter were measured in each station during high and low tide. The ecological parameters frequency, dominance, constancy and clustrer analysis in hierarchy dendogram, were used to characterize quantitatively Guaratiba's mangrove.

Physical-chemical parameters showed small oscillations between high and low tide with values close to marine's conditions. Bacalhau Channel showed pH 8.0-8.5, salinity 30.6-35.5\%o and 4-22mg/l of suspended matter. Forty one species of foraminifera were identified with an average of 14 species per station, where the dominance was Textularidae followed by Rotalidae Allogromiidae 
and Miliolidae. Others were represented with few species and specimens. The most constant species were $A$. mexicana, $H$. wiberti ad $T$. inflata present in all stations. Dominance was of A.mexicana with a frequency of 37-92\%. Both the Piracão and Portinho rivers showed the largest values of species richness and frequency in upstream and downstream direction. But along the Bacalhau Channel there was a uniform distribution. Cluster analysis indicates existence of four foraminiferal assemblages along the channels:

$\circ$ Assemblage I - related to high salinity and low $\mathrm{pH}$, located in the stations upstream of Portinho and Piracão rivers;

- Assemblage II - related to high salinity located along Piracão River;

○ Assemblage III - related to mangrove's unstable environment, located along Portinho River;

○ Assembly IV - related to the marine environment in the mangrove, where salinity is higher and suspended matter was lower located close to the waterway that comunicates with the ocean.

Guaratiba's mangrove tidal channels are physio-chemically stable showing a great diversity of typical paralic environments species. The dominance of $A$. mexicana was greater where the physical-chemical parameter oscilations were small. The species richness in Bacalhau Channel might be explained by the contact with ocean. The inverse occurs with Piracão River that showed the lowest values of salinity and the highest diversity of Allogromidae. The cluster was satisfactory, allowing us to establish a model of assemblages distribution along the channels. Additionally, this distribution seemed to be regulated by salinity and suspending matter. The results of these samples collected in the end of 70's, may be used as a background reference to ecosystem monitoring studies specially considering present conditions imposed by industry and harbor activities. 